\title{
Correction to: Use of cork granules as an effective sustainable material to clean-up spills of crude oil and derivatives
}

\author{
Diego Todescato $^{1,2} \cdot$ Fabíola V. Hackbarth $^{2}$ • Pedro J. Carvalho ${ }^{3}$ • Antônio A. Ulson de Souza ${ }^{2}$. Selene M. A. G. Ulson de
} Souza $^{2} \cdot$ Rui A.R. Boaventura ${ }^{1} \cdot$ Miguel A. Granato ${ }^{4}$ - Vítor J. P. Vilar ${ }^{1}$ (D)

Published online: 19 December 2019

(C) Springer-Verlag GmbH Germany, part of Springer Nature 2019

\section{Correction to: Environmental Science and Pollution Research} https://doi.org/10.1007/s11356-019-06743-1

The original publication of this paper contains a mistake.

The correct title is shown in this paper.

The original article was corrected.

The online version of the original article can be found at https://oi.org/ 10.1007/s11356-019-06743-1

Vítor J. P. Vilar

vilar@fe.up.pt

1 Laboratory of Separation and Reaction Engineering-Laboratory of Catalysis and Materials (LSRE-LCM), Chemical Engineering Department, Faculty of Engineering, University of Porto, Rua Dr. Roberto Frias, 4200-465 Porto, Portugal

2 Laboratory of Mass Transfer, Federal University of Santa Catarina, PO Box 476, Florianópolis, SC CEP 88040-900, Brazil

3 CICECO-Aveiro Institute of Materials, Department of Chemistry, University of Aveiro, 3810-193 Aveiro, Portugal

4 Departamento de Engenharias, Universidade Federal de Santa Catarina (UFSC), Campus Blumenau, Blumenau, SC, Brazil 